\title{
Late clinical and magnetic resonance imaging follow up of Nipah virus infection
}

\author{
C C T Lim, W L Lee, Y S Leo, K E Lee, K P Chan, A E Ling, H Oh, A P Auchus, N I Paton, \\ F Hui, P A Tambyah
}

J Neurol Neurosurg Psychiatry 2003;74:131-133

\begin{abstract}
The Nipah virus is a newly identified paramyxovirus responsible for an outbreak of fatal encephalitis in Malaysia and Singapore. This paper reports the follow up clinical and magnetic resonance imaging findings in 22 affected subjects. Of 13 patients with encephalitis, one died, one was lost to follow up, and seven recovered. Among the four remaining patients, one had residual sixth nerve palsy, another suffered from severe clinical depression, and a third patient had evidence of retinal artery occlusion. One patient with delayed onset Horner syndrome had a single lesion in the cervical spinal cord. The brain magnetic resonance findings were stable or improved in nine patients over 18 months of follow up. Among a second group of nine asymptomatic seropositive abattoir workers, magnetic resonance examination in seven subjects revealed discrete small lesions in the brain; similar to those detected in encephalitis patients. These findings suggest that in addition to encephalitis, the newly discovered Nipah virus affects the spinal cord and the retina. Late clinical and radiological findings can occur in Nipah virus infections as with other paramyxoviruses.
\end{abstract}

A n outbreak of fatal encephalitis occurred among pig farmers in Malaysia in 1998-1999. ${ }^{2}$ In neighbouring Singapore, which imported live pigs from Malaysia, the outbreak affected only abattoir workers. ${ }^{3-5}$ A newly discovered member of the Paramyxoviridae family, named the Nipah virus, ${ }^{67}$ was found to be the causative agent.

Named after the village in Malaysia where the virus was first discovered, the Nipah virus is closely related to the Hendra virus, ${ }^{6}$ another recently isolated paramyxovirus responsible for disease in horses and humans in Australia. ${ }^{8}$ As the Nipah virus is a novel pathogen, its long term effects are unknown. In the Hendra virus outbreak, there was one case of fatal encephalitis after a 13 month latency period. ${ }^{9}$ Furthermore, there have been reports of neurological relapse and late onset encephalitis among Malaysian Nipah virus patients. ${ }^{10}{ }^{11}$

We describe the follow up clinical and radiological findings in two groups of pig workers affected by the Nipah virus outbreak.

\section{METHODS}

\section{Subjects}

Twenty two subjects who had serological evidence of Nipah virus infection were studied. All had been exposed to live pigs and were positive on enzyme immunoassay using a protocol developed by the Centers for Disease Control (Atlanta, GA). ${ }^{1}$ The subjects were divided into two groups: the first group comprised 13 patients who suffered from Nipah virus encephalitis during the outbreak. The second, asymptomatic group consisted of nine abattoir workers who were clinically well, but were found on screening to have serological evidence of Nipah virus infection.

\section{Study design}

Clinical records and magnetic resonance (MR) data were collected prospectively. Subjects were followed up at three monthly intervals. Serial brain imaging studies were obtained in the encephalitis patients during the outbreak (day l to 38 ), and again at 6 months, 12 months, and 18 months. T1 and T2 weighted, fluid attenuated inversion recovery (FLAIR), diffusion weighted, and contrast enhanced pulse sequences were performed on $1.5 \mathrm{~T}$ clinical scanners. Among the asymptomatic group, brain MR imaging was carried out between four months and 14 months after the outbreak, with four subjects undergoing two or more studies. Cervical spine MR imaging performed in patient 2 consisted of T1 and T2 weighted as well as contrast enhanced sequences. Institutional review board approval and informed consent were obtained for our study.

\section{RESULTS}

\section{Encephalitis group}

Table 1 summarisies the clinical and radiological findings. During the virus outbreak, all 13 patients were symptomatic with acute encephalitis. Five were comatose, requiring intensive care. Focal neurological deficits included cerebellar signs, motor and/or sensory loss, and transient myoclonus. Visual symptoms affected five patients, ranging from diplopia and nystagmus, to blurred vision or transient blindness. ${ }^{34}$ Findings on initial MR imaging have been previously reported.12 ${ }^{13}$ Multiple discrete small lesions were detected in the cerebral white matter, also involving the cortex, pons, cerebral and cerebellar peduncles, and the putamen.

Patient 1 died of his illness, and patient 10 was lost to follow up immediately after discharge from hospital. Of the 11 patients who returned for multiple outpatient visits, seven recovered with no residual neurological deficits. Patient 2 suffered from residual dysmetria and broad based gait, left arm dysaesthesia, and finger weakness. Nine months after the outbreak, he developed left Horner syndrome, with ptosis, miosis, and absence of sweating over the left side of his forehead. Electromyography and nerve conduction studies revealed denervation in the left C8-Tl innervated muscles. MR examination of the cervical spine showed a single small lesion at C7 level of the spinal cord (fig 1). IgG but not IgM antibodies were present in the cerebrospinal fluid, Nipah virus culture was negative. This was presumed to be attributable to a late manifestation of Nipah virus infection as no other cause could be elicited.

Patient 3 suffered persistent diplopia caused by sixth nerve palsy. Patient 4 had residual monoparesis and nystagmus, and was re-admitted to hospital 16 months after the outbreak with severe depression and suicidal thoughts. He declined further psychiatric evaluation. Patient 7 complained of blurred vision in the left eye a month after discharge from hospital. 
Table 1 Clinical and MR imaging findings in Nipah virus encephalitis patients

\begin{tabular}{|c|c|c|c|c|c|c|}
\hline \multirow[b]{3}{*}{$\begin{array}{l}\text { Patient no/ } \\
\text { sex/age }\end{array}$} & \multicolumn{3}{|c|}{ At outbreak } & \multicolumn{3}{|c|}{ At 18 month surveillance } \\
\hline & \multicolumn{2}{|c|}{$\begin{array}{l}\text { Number of lesions } \\
\text { on MR imaging }\end{array}$} & \multirow[b]{2}{*}{ Clinical condition } & \multicolumn{2}{|c|}{$\begin{array}{l}\text { Number of lesions on } \\
\text { MR imaging }\end{array}$} & \multirow[b]{2}{*}{ Residual clinical signs } \\
\hline & $\begin{array}{l}\text { White } \\
\text { matter }\end{array}$ & $\begin{array}{l}\text { Other } \\
\text { sites }\end{array}$ & & $\begin{array}{l}\text { White } \\
\text { matter }\end{array}$ & $\begin{array}{l}\text { Other } \\
\text { sites }\end{array}$ & \\
\hline $1 / M / 47$ & 4 & 4 & Coma, seizures, died on 3rd hospital day & Not done & Not done & Deceased \\
\hline $2 / M / 42$ & 20 & 0 & Coma, cerebellar signs, monoparesis & 5 & 2 & $\begin{array}{l}\text { Finger weakness, left arm dysaesthesia, } \\
\text { delayed Horner syndrome }\end{array}$ \\
\hline $3 / M / 37$ & 50 & 11 & $\begin{array}{l}\text { Coma, cerebellar signs, diplopia, tetraparesis, } \\
\text { sensory loss, areflexia }\end{array}$ & 3 & 0 & $\mathrm{VI}$ palsy \\
\hline $4 / M / 55$ & 6 & 16 & $\begin{array}{l}\text { Coma, cerebellar signs, nystagmus, areflexia, } \\
\text { monoparesis, transient myoclonus }\end{array}$ & 6 & 7 & $\begin{array}{l}\text { Monoparesis, nystagmus, suicidal } \\
\text { depression }\end{array}$ \\
\hline $5 / M / 41$ & 40 & 12 & Stupor & 3 & 4 & No residual neurological deficit \\
\hline $6 / F / 51$ & 10 & 13 & Cerebellar signs, $\mathrm{VI}$ palsy & 1 & 0 & No residual neurological deficit \\
\hline $7 / M / 24$ & 8 & 3 & Blurred vision & 3 & 1 & Branch retinal artery occlusion \\
\hline $8 / M / 65$ & 22 & 6 & $\begin{array}{l}\text { Cerebellar signs, diplopia, VI palsy, Horner } \\
\text { syndrome, dysphonia, transient myoclonus }\end{array}$ & - & - & No residual neurological deficit \\
\hline $9 / M / 45$ & 26 & 10 & Cerebellar signs & 15 & 2 & No residual neurological deficit \\
\hline $10 / M / 24$ & 30 & 2 & Transient blindness & - & - & Lost to follow up \\
\hline $11 / M / 55$ & 7 & 1 & Hallucinations & - & - & No residual neurological deficit \\
\hline $12 / M / 48$ & 30 & 3 & Headache & 14 & 0 & No residual neurological deficit \\
\hline $13 / M / 24$ & 5 & 2 & Coma & 4 & 1 & No residual neurological deficit \\
\hline
\end{tabular}

Ophthalmological review showed branch retinal artery occlusion, confirmed on fluorescein angiography.

Nine patients underwent serial brain MR studies over 12 to 18 months after the outbreak. Most brain lesions disappeared or were smaller, but some remained unchanged on multiple examinations.

\section{Asymptomatic group}

All nine asymptomatic subjects (all men, mean age 50.1 years) were clinically well during the outbreak and follow up. They were among 521 exposed abattoir workers who underwent mass serological screening immediately after the outbreak. ${ }^{14}$ Except for one man who had a history of hypertension, there was no other coexisting illness such as diabetes mellitus.

Seven subjects had abnormalities on T2 weighted and FLAIR MR imaging. Small, hyperintense lesions less than 1 $\mathrm{cm}$ in size were detected in the cerebral white matter, cerebral peduncles, putamen, and pons. None of the lesions enhanced with contrast or were abnormal on diffusion weighted MR

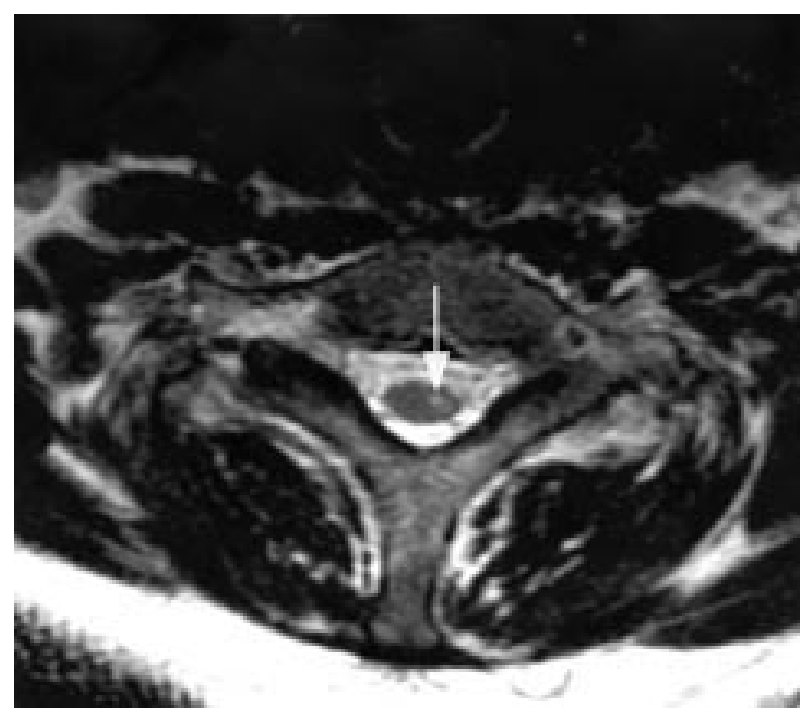

Figure 1 T2 weighted axial MR image of the cervical spine of patient 2 shows a small hyperintense lesion (arrow) in the spinal cord. sequences. Four patients underwent repeat MR imaging, which showed no change in the number, size and location of lesions.

\section{DISCUSSION}

We followed up subjects infected by a new paramyxovirus to determine if they would develop clinical relapse of encephalitis or late onset neurological disease. Measles, the best studied paramyxovirus, is known to cause persistent brain infection, leading to subacute sclerosing panencephalitis. The novel zoonotic paramyxoviruses, Hendra and Nipah, ${ }^{6}$ have also been documented to cause delayed fatal complications, with the brain MR pattern changing to confluent cortical lesions.. ${ }^{90}$ Three patients had persistent, and one had new clinical symptoms during the follow up period (patients 2, 3, 4, and 7). However, surveillance with serial brain MR imaging did not reveal new lesions, suggesting a possible post-infectious or immune mediated pathophysiology for the clinical findings.

Clinical manifestations and MR lesions may have fully developed in patient 2 only in the months after the initial infection. We believe this to be the first report of spinal cord Nipah virus lesion confirmed by MR imaging, although signs such as segmental myoclonus, flaccid tetraplegia, and nerve conduction studies have suggested spinal cord involvement in other reported series. ${ }^{7}$ Infection of the spinal cord by the poliovirus, echovirus, and cryptococus ${ }^{15-17}$ has been reported. Our finding of combined encephalitis and myelitis bears some similarity to the 1998 enterovirus 71 outbreak of encephalomyelitis in Taiwan, where abnormalities were also detected in both the brain and spine by MR imaging. ${ }^{18}$

Postmortem studies of Nipah virus patients have demonstrated widespread endothelial infection of the small blood vessels in the central nervous system, leading to thrombotic occlusion and microinfarction. ${ }^{2}$ The brain MR findings of small lesions in the deep cerebral white matter in our patients would be consistent with vasculitic small vessel infarction. ${ }^{12}{ }^{13}$ Our finding of small retinal artery occlusion in patient 7 has not been described previously in Nipah virus infection, and would also be consistent with this hypothesis.

Clinical depression as a consequence of organic brain damage has been described in a number of situations. However, an alternative explanation may be reactive depression brought about by protracted illness and disability, with attendant effects on the patient's family and livelihood. Unfortunately, 
patient 4 refused all further evaluation and medical treatment and we are unable to conclude further.

MR imaging in the asymptomatic group of exposed abattoir workers revealed abnormalities that were similar in size, location, and signal intensity to those found in encephalitis patients, suggesting that the lesions are also caused by Nipah virus infection (Y S Leo, et al, International conference on emerging infectious diseases, 2000 and Tan et al). ${ }^{19}$ Unfortunately, it was not possible to carry out MR imaging during the acute outbreak in the asymptomatic group of patients. Without direct evidence of acute infection such as contrast enhancement or diffusion hyperintensity, ${ }^{12}$ the possibility of pre-existing lesions from other causes, ${ }^{20}$ cannot be entirely eliminated. However, the absence of diabetes, hypertension, or other risk factors for small vessel occlusive disease in our population makes it highly probable that Nipah virus infection caused the brain lesions seen on MR imaging.

In our follow up study, we found no clinical or radiological evidence of late onset or relapsing disease in the brain. However, we found that this novel pathogen affects the spinal cord and the retina, probably from occlusion of small blood vessels. Furthermore, MR imaging evidence suggests that subclinical brain infection occurred among exposed abattoir workers. These findings expand the spectrum of clinical involvement of Nipah virus from that previously described. We believe that as more information emerges about the reservoir and pathophysiology of this novel pathogen, we will have a clearer understanding of its clinical manifestations and the implications for its control.

\section{ACKNOWLEDGEMENTS}

This study was partly funded by the National Medical Research Council of Singapore grant NRN99/05. We thank Doctors Lim Tock Han, Ng Beng Yong, Nigel Tan, and Angela Tan for their assistance.

\section{Authors' affiliations}

C C T Lim, F Hui, Department of Neuroradiology, National Neuroscience Institute, Singapore

W L Lee, K E Lee, Department of Neurology, National Neuroscience Institute

Y S Leo, N I Paton, Department of Infectious Disease, Tan Tock Seng Hospital, Singapore

K P Chan, A E Ling, Department of Pathology, Singapore General Hospital, Singapore

H Oh, Department of Medicine, Changi General Hospital, Singapore

A P Auchus, Department of Neurology, Singapore General Hospital

P A Tambyah, Department of Medicine, National University Hospital, Singapore

Competing interests: none declared.
Correspondence to: Dr C C T Lim, Department of Neuroradiology, National Neuroscience Institute, 11 Jalan Tan Tock Seng, Singapore 308433; tchoyoson_lim@.ttsh.com.sg

Received 5 April 2002

Accepted in revised form 21 August 2002

\section{REFERENCES}

1 Centers for Disease Control and Prevention. Outbreak of Hendra-like virus-Malaysia and Singapore, 1998-1999. MMWR Morb Mortal Wkly Rep 1999;48:265-9.

2 Chua KB, Goh KJ, Wong KT, et al. Fatal encephaltis due to the Nipah virus, a new paramyxovirus among pig farmers in Malaysia. Lancet 1999;354:1257-9.

3 Lee KE, Umapathi T, Tan CB, et al. The neurological manifestations of Nipah virus encephalitis, a novel paramyxovirus. Ann Neurol 1999;46:428-32

4 Paton NI, Leo YS, Zaki SR, et al. Outbreak of Nipah-virus infection among abattoir workers in Singapore. Lancet 1999;354:1253-6.

5 Lim CCT, Sitoh YY, Lee KE, et al. Meningoencephalitis caused by a novel paramyxovirus: An advanced MRI case report in an emerging disease. Singapore Med J 1999;40:356-8

6 Chua KB, Bellini WJ, Rota PA, et al. Nipah virus: a recently emergent deadly paramyxovirus. Science 2000;288:1432-5.

7 Goh KJ, Tan CT, Chew NK, et al. Clinical features of Nipah virus encephalitis among pig farmers in Malaysia. N Engl J Med 2000;342:1229-35.

8 Murray K, Selleck P, Hooper P, et al. A morbillivirus that caused fatal disease in horses and humans. Science 1995:268:94-7.

9 O'Sullivan JD, Allworth AM, Paterson DL, et al. Fatal encephalitis due to novel paramyxovirus transmitted from horses. Lancet 1997;349:93-5.

10 Sarii SA, Abdullah BJ, Goh KJ, et al. MR imaging features of Nipah encephalitis. AJR Am J Roentgenol 2000;175:437-42.

11 Wong SC, Ooi MH, Wong MN, et al. Late presentation of Nipah virus encephalitis and kinetics of the humoral immune response. J Neurol Neurosurg Psychiatry 2001;71:552-4

12 Lim CCT, Sitoh YY, Hui F, et al. Nipah viral encephalitis or Japanese encephalitis? - MR findings in a new zoonotic disease. AJNR Am J Neuroradiol 2000;21:455-61.

13 Lim CCT, Lee KE, Lee WL, et al. Nipah virus encephalitis: serial MR study in an emerging disease. Radiology 2002;222:219-26.

14 Chan K P, Rollin P E, Ksaizek T G, et al. A survey of Nipah virus infection among various risk groups in Singapore. Epidemiol Infect 2002; 128:93-8.

15 Kornreich L, Dagan O, Grunebaum M. MRI in acute poliomyelitis. Neuroradiology 1996;38:371-2.

16 Malzberg MS, Rogg JM, Tate CA, et al. Poliomyelitis: hyperintensity of the anterior horn cells on MR images of the spinal cord. AJR Am J Roentgenol 1993;161:863-5.

17 Grosse P, Tintelnot K, Sollner O, et at. Encephalomyelitis due to Cryptococcus neoformans var gattii presenting as spinal tumor: case report and review of the literature. J Neurol Neurosurg Psychiatry 2001;70:1113-16.

18 Huang CC, Liu CC, Chang YC, et al. Neurologic complications in children with enterovirus 71 infection. N Engl J Med 1999;341:936-42.

19 Tan KS, Sarii SA, Tan CT, et al. Patients with asymptomatic Nipah virus infection may have abnormal cerebral MR imaging. Neurological Journal of South East Asia 2000;5:69-73.

20 Awad IA, Spetzler RF, Hodak JA, et al. Incidental lesions noted on magnetic resonance imaging of the brain: prevalence and clinical significance in various age groups. Neurosurgery 1987;20:222-7. 